\title{
El mito del editor
}

\author{
José Luis Sandoval-Gutiérrez
}

Secretaría de Salud, Instituto Nacional de Enfermedades Respiratorias, Servicio de Neumología, Ciudad de México, México

En el número 3 de 2017 de Gaceta Médica de México, Espinosa-Larrañaga ${ }^{1}$ presenta un editorial interesante sobre la labor del editor de una revista científica y su responsabilidad en mejorar la calidad de esta. El título de la presente comunicación tiene el mismo nombre que utilizó Adolfo Castañón, exdirector del Fondo de Cultura Económica, en un ensayo publicado en 1993. ${ }^{2}$

Es importante señalar que para que exista una revista con relevancia académica, se necesita contribuciones acordes con esa situación.

En México, la cantidad de investigadores de relevancia se incrementa año con año; la posibilidad de estudiar un posgrado en el extranjero y el intercambio académico permiten esa nueva realidad.

El problema radica en que para estar en el estándar de investigación de alto nivel se exige publicar en revistas con alto impacto, que en su mayoría están en idioma en inglés y son generadas en otras naciones, aunque actualmente en nuestro país existen dos revistas médicas que cumplen con dicho requisito. ${ }^{3,4}$

El científico que se encuentra en el Sistema Nacional de Investigadores necesita cumplir con un método de puntuación para permanecer y promoverse en el mismo; infortunadamente, las revistas nacionales le proporcionan poca calificación, por lo que el investigador omite de primera instancia esa posibilidad de contribución.
Por todo lo anterior se forma un círculo vicioso: un artículo original no es enviado a una revista que da pocos puntos sino a otra considerada con mayor impacto, por lo que la primera sigue sin recibir trabajos de mayor calidad.

La pregunta es ¿cómo rompemos con esa inercia? Con un sistema de incentivos y estímulo, sería conveniente que dentro de lo que se exige al profesional en el Sistema Nacional de Investigadores se considere una participación por porcentaje de sus investigaciones a revistas mexicanas como promoción científica nacional y que la puntuación otorgada sea acorde con lo publicado en las de mayor ranking. Para que la ciencia de un país funcione, no solo se requiere recurso humano de alta calidad sino también órganos de difusión acordes con ese nivel.

El mito del editor se puede ir esclareciendo al existir un compromiso de todos los actores involucrados en la investigación, para beneficio de la ciencia y los pacientes.

\section{Bibliografía}

1. Espinosa-Larrañaga F. La calidad de una publicación científica es resultado de esfuerzos y atributos. Gac Med Mex. 2017;153(3):293-296.

2. Castañón A. El mito del editor y otros ensayos. México: Miguel Ángel Porrúa; 1993.

3. Elsevier. [Sitio web]. Archives of Medical Research. [Consultado 2018 Ene 18]. Disponible en: https://www.journals.elsevier.com/archives-of-medical-research/.

4. Revista de Investigación Clínica. [Sitio web]. Revista de Investigación Clínica/Clinical and Translational Investigation. [Consultado 2018 Ene 19]. Disponible en: http://clinicalandtranslationalinvestigation.com. 